\title{
Online Problem-based Learning Approach in Higher Education.
}

\author{
Roisin Donnelly \\ Technological University Dublin, roisin.donnelly@tudublin.ie
}

Follow this and additional works at: https://arrow.tudublin.ie/ltcbk

Part of the Educational Methods Commons, and the Higher Education Commons

\section{Recommended Citation}

Donnelly, R. (2007). Online Problem-based Learning Approach in Higher Education. In L. Tomei (Ed.), Online and Distance Learning: Concepts, Methodologies, Tools and Applications. Hershey, PA: Information Science Reference, 2007.

This Book Chapter is brought to you for free and open access by the Learning Teaching \& Assessment at ARROW@TU Dublin. It has been accepted for inclusion in Books/Book Chapters by an authorized administrator of ARROW@TU Dublin. For more information, please contact arrow.admin@tudublin.ie, aisling.coyne@tudublin.ie,gerard.connolly@tudublin.ie.

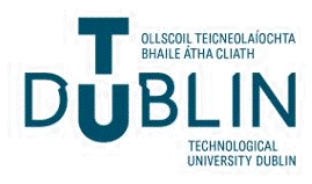




\title{
Online Problem-Based Learning Approach in Higher Education
}

\author{
Roisin Donnelly \\ Dublin Institute of Technology, Ireland
}

\section{INTRODUCTION}

This paper begins with a brief review of the history of problem-based learning (PBL) integrated with online learning, and surveys relevant learning theory, including constructivism and cognitivism. Recent case-study research on a postgraduate diploma module in learning and teaching for faculty and lecturers in higher education is then provided to illustrate the key issues for both faculty and students in this evolving area. Emerging trends in combining PBL and online learning are outlined, along with potential opportunity to continue to research the topic in a different light. The paper concludes with an overview of the research area, aspects of which have been confirmed as strengths, and others that have been highlighted for change.

Online learning in higher education is a relatively young field that is still being defined as a discipline. As faculty members wrestle with decisions about how to structure online courses for collaborative, connected learning, student perspectives of successful courses can provide valuable insights for decision making. While online learning offers students many advantages over campus-based learning, problems do exist. One such problem is the attrition rate of online learners, brought about in large part by a sense of isolation. One teachinglearning model, which can ameliorate this sense of isolation, is problem-based learning.

\section{HISTORICAL PERSPECTIVE}

Problem-based learning originated in medical schools based on seeking solutions to real-world problems. Through working cooperatively in groups, thinking critically, and finding and using learning resources, PBL encourages students in their learning and provides faculty with an innovative method of teaching.
In general, PBL is a method of instruction that uses problems as a context for students to acquire problem-solving skills and basic knowledge. Vernon and Blake (1993) further characterize PBL as the study of real or hypothetical cases in small discussion groups engaged in collaborative, independent study using hypothetico-deductive reasoning with a style of faculty direction that concentrates on group process rather than provision of information.

In terms of the history of PBL in higher education, Boud and Feletti (1991) suggest that "the notion of problem-based learning is not new; it was the way in which learning took place before the advent of classrooms and curricula." They further argue that the "newness" lies in the way that learning has been linked to professional practice to allow the development of "highly competent practitioners who have the ability to continue to learn effectively throughout their lives." Certainly, the origins of problem-based learning, and its continuing focus, lie in the education of professionals. While the introduction of problembased learning in the mid-1960s is credited to staff in the medical school at McMaster University in Canada, it is noted that soon after, three other medical schools - the University of Limburg at Maastricht in the Netherlands, the University of Newcastle in Australia, and the University of New Mexico in the United States-adapted the McMaster model of problem-based learning, and that from these four institutions sprang one of the more important higher educational movements of the 20th century.

Linking PBL to online learning, Albion and Gibson (1998) argue that "PBL has not been widely reported as an instructional design for interactive multimedia (IMM), almost certainly due to the emphasis on group interaction as a component of typical PBL implementations and the individualized nature of IMM." There is, however, a growing collection of papers reporting research and projects that explore the possibilities for instructional design based on the 
principles of constructivism. With many of the features of PBL recognizable as central to social constructivism, it is reasonable then to argue that the design of online environments and interactive multimedia to support a constructivist philosophy could well be adaptable for problem-based learning.

In support of the connection made between PBL and constructivism, Savery and Duffy (1995) present a case for an instructional model for problem-based learning embedded in a constructivist framework. To support, enhance, or deliver problem-based learning in the online environment, the elements of problem-based learning identified as "essential" by Barrows (1986) must be considered, and it would seem sensible to expect that a modification of the PBL approach might be made in line with the constraints of the online environment and that technology should be designed or adopted to encompass these essential elements.

Certainly amongst Barrow's list of PBL essentials, there are a number that emerge as problematic when face-to-face teaching is not in place. There is an expectation that discussion, and cooperative and collaborative activity, will continue within groups during the resolution of a particular problem. Additionally, for students to progress to deeper levels of thinking, critical analysis of aspects of the problem and possible solutions, and the comparative evaluation of personal understandings against those of others, are seen as essential, as are other metacognitive processes. The role of the tutor or facilitator to question, encourage, and support students so that they develop the necessary reflective and critical thinking skills is of paramount importance. It is necessary, then, to be able to answer with a technological solution the question of, "What form of online environment might be created to support these essential processes?"

A search of the literature and the World Wide Web (WWW) would identify that there is a relatively recent wealth of examples of PBL being conducted online to varying degrees. McMaster University undertook a literature review in 2001 to examine research papers that studied the use of computermediated communication (CMC), problem-based learning, and/or collaborative learning in higher education. Their database of articles was developed as part of a larger research study. Central Queensland University has developed a Web site devoted to the world's best practice on online collaborative learning in higher education, with some related topics exploring facets of online PBL.

With these developments in mind, working over a number of years in both problem-based learning and online learning, current case-study research was conducted combining the two areas in search of a learning environment for students that would bring together the best that each had to offer.

\section{MAIN THRUST}

Prior to the online-learning and PBL module on the postgraduate diploma in third-level learning and teaching being designed, an international literature review was conducted to further seek out the relationship between online learning and problem-based learning, with the intent to first review research in the two areas individually and then in a combined setting. As the setting for this research was a postgraduate faculty-lecturer course, with intensive support provided to course participants, the literature pointed to the need to maintain and provide ubiquitous and individualized teaching and learning support for staff at the tertiary level, and indicated that this is a growing concern worldwide (Gardner, Sheridan, \& White, 2002). Chuang (2002) discussed a teachertraining program that focuses on technology and approaches to learning, amongst others, as problembased learning and a social-constructivist approach. Similar to this online PBL module, participants are involved in small group discussion with real-world questions that fit with the local context.

To begin a PBL process online, students generally work in a small group of between 8 to 10 members through a Web-based learning environment, and therein they encounter challenging situations with undefined problems, incomplete information, and unasked questions. Problem-based learning is particularly suited to assist students toward mastery in a range of generalisable competencies and to support effective adult learning in the cognitive and affective aspects of a course in higher education (Engel as cited in Boud \& Feletti, 1991). The online learning environment (OLE) adds a further dimension to this as students today realise the need for and benefit of anytime, anyplace collaboration. The problems presented online to the students in their PBL 
group demand problem solving the way it exists in real life. This can be broken into a number of key stages. First, the students can spend time identifying, defining, and detailing facts and learning issues of the situation. Alongside this, they create hypotheses. Second, they conduct their investigations through the collection of data (could be primary or secondary). Third, they develop solutions that fit the conditions of the problem. Finally, they evaluate and justify potential solutions based upon their likelihood to produce wanted effects.

The authentic problem on which the PBL group can focus their energies is written to reflect the fact that learning occurs in various ways in the workplace. Often, learning occurs as part of a process of endogenous growth (Trentin, 2001) through mechanisms such as trial and error, problem sharing and solving, and informal contacts with peers. Collis and Winnips (2002) advocate that mentoring relationships are important opportunities for learning in the workplace, but generally occur without any reference to a conceptual framework for learning support. They argue that what is often missing is an explicit orientation toward learning from the experiences of the other course participants. In this case study of an online PBL module, an informal peer-mentoring system was established within this module to provide such support for those lecturers having problems with the online technology. This, coupled with the PBL group process itself, was regarded by the module tutor as a vital part of the support to the overall learning process for the lecturers.

Recent developments of advanced information and communication technologies have spawned a great deal of research on how these technologies feature in different learning activities (Arnseth et al., 2001). The related issue of cognition, or the relation between cognition, collaboration, and different kinds of ICT tools, has also been, and is, an issue that is both prominent and widely discussed within the field of computer-supported cooperative learning (CSCL; Dillenbourg, 1999; Lehtinen et al., 2000; Littleton \& Light, 1999).

Collaborative teamwork is an essential aspect of problem-based learning. Students are required to share and review information sources, develop an understanding of the learning issues involved in the problem, and develop responses to the issues identified within the problem. The ability to communicate online as a group using discussion boards and e-mail lists, and to share documents as attachments to these messaging systems provides a flexible, easily accessed method for collaboration. In $\mathrm{WebCT}^{\mathrm{TM}}$, it is possible to have shared documents available to a group from the course server.

The key to success is using the principles of problem-based learning to share valuable information with peers from potentially a variety of other subject disciplines, experiences, and personalities. The OLE provides the PBL group with an opportunity to enhance their group learning in a real-life, multidisciplinary learning environment. Therefore, going through this PBL process enables the students to crisscross domains of knowledge, making interdisciplinary connections. They develop skills and subject-matter content needed to make the transition from novice to more expert problem solver. The students build substantial knowledge bases, enter into real online collaborations with classmates, and gain experience in solving authentic problems.

Using the Internet for problem solving introduces new dimensions to teaching. These new tools and resources require the development of new skills on the part of both the teacher and the students. The teacher must bring actual problems into the curriculum and students need Internet resources to deepen their understanding of the learning issues.

From the problem-based-learning group perspective, undertaking a range of group roles within an online discussion forum can be explored along with designing materials online that will teach the key skills of developing effective teamwork skills and effective and efficient self-directed study skills.

Scholars have been advocating the benefits of an online problem-based learning approach. It has been asserted that technology-mediated learning can play an important role in the problem-solving process (Hedberg, 2000). Although face-to-face collaborative learning techniques have been shown to enhance the learning experience, it is difficult to incorporate these concepts into courses without requiring students to collaborate outside of class (Ocker \& Yaverbaum, 2001). The results of research indicate that although students preferred to collaborate in the traditional face-to-face manner, they realised the need for and benefit of anytime, anyplace collaboration. 
Research has also shown that there are a number of instructional strategies that can be well supported through modern interactive learning environments. Whether it be an individual problem presented on CD-ROM or Web-based collaboration, there are many advocates for problem-based learning as a framework for motivating learners and generating high-quality learning outcomes.

Computer-mediated communication including Web pages, e-mail, and Web-based discussion fora have been reported by students using them as assisting in increasing satisfaction with their studies, decreasing feelings of isolation, and providing better support for their learning processes (Geelan \& Taylor, 2001).

As the use of information and communications technologies becomes more widely used to support education programs such as this, faculty and designers need to look at strategies that provide a rich and engaging learning environment that is centred around the students' learning needs. The move to learnercentred learning does not need to occur online, but if online learning is established, then it must be based on a learner-centred model. In the past, one of the failures of online learning has been the concept that placing information on the Internet is all that is needed for students to be able to learn effectively online.

As institutions embrace technology, designers and developers should endeavour to use effective strategies that emulate the instructor-student interaction of a traditional classroom, and engage the students in an active learning process by applying problem-solving strategies and modeling that use many different forms of instructional technology. These methods should provide authentic experiences with adaptive learning contexts that enable the learner to immediately apply the knowledge gained (Atkinson, 2001).

The incorporation of a problem-based learning strategy into an online learning environment provides the engaging, collaborative, and learner-centred activities that are required to encourage a student to fully participate in the learning program. Interaction can take place because the connectedness of the Internet allows students to communicate more freely than in class-based work. Threaded discussions and bulletin boards enable communications to grow over a period of time. These methods provide not only an effective way of communicating, but also provide a record of people's contributions. Synchronous communications such as chat means that students can work in groups at times other than during class times, providing for a degree of flexibility in the way students can participate in the learning activities.

In effect, in this learning environment, information is the raw material for thinking and the construction of new knowledge. When combining PBL and ICT, resolution of the problems require that students search for new information on the WWW and build their knowledge base through investigation and inquiry.

Interaction is a critical component of a constructivist learning environment via the Web because learning occurs in a social context through collaboration, negotiation, debate, and peer review (Grabinger \& Dunlap, 2000). Of the various forms of interaction that can take place online, there are three critical components to this interaction. First, an academic (learner-to-content) component can occur when the students access online materials and receive task-oriented feedback from the tutor. Second, a collaborative (learner-to-learner) component can occur when the students are engaged in discourse, problem solving, and product building using the facilities in the online learning environment. This integration component helps the students validate their learning experiences, and requires a level of reflective articulation that promotes collective knowledge building and a deeper personal understanding of what is being studied. Finally, an interpersonal and social component can occur when the students receive feedback from faculty, tutors, or peers, such as in the form of personal encouragement and motivational assistance. Social interaction can contribute to learner satisfaction and frequency of interaction in an online learning environment. Without the opportunity to actively interact and exchange ideas with each other and the tutor, the student's social as well as cognitive involvement in the learning environment will be diminished.

In developing the solution to most problems online, students need to access a range of information sources to develop a well-thought-out solution to the problem. By working in a collaborative environment in which the students share the results of their investigation, the student is able to achieve a deeper and more complete understanding of the problem. 
The sharing of information allows the development of interpersonal skills that reflect the ways in which people need to work on a day-to-day basis. Sharing also brings to the problem-solving process a variety of views that will need to be considered. Learners will need to negotiate the relevance and importance of information in developing solutions to the problem.

Jonassen (1997) explored instructional design models for well-structured and ill-structured problem-solving learning outcomes. Although he does not restrict himself to a problem-based learning approach in his delineation of instructional design principles intended to engage students with ill-structured problems, and he does not position this model in an online environment, it can be argued that the model could well inform online design for problembased learning.

All the findings from this literature review were an important consideration in the design of the module.

\section{THE AUTHOR'S PERSPECTIVE}

The author's perspective and research in this area is supplemented by an awareness of current national and international research and strategies related to both problem-based learning and online learning in higher education. In the light of both the benefits and challenges of merging these two approaches to course design and delivery, the author wishes to present an outline of an online teaching environment that adopted problem-based learning as its primary learning approach. The module was a component of a postgraduate diploma in third-level learning and teaching for lecturers from a range of higher education institutions in the Republic of Ireland.

Figure 1

\section{PLEASE SUBMIT}

The aim of the module is to enable lecturers to become aware of the theories and practicalities of designing, delivering, supporting, and evaluating an online module in their own subject discipline; the key to their success is using the principles of problembased learning to share valuable information about online learning with their multidisciplinary peers.

The PBL approach used involves the lecturers working together typically in a group of between four to six in order to develop an online module in one of their own subject disciplines. The beginning point for the PBL group is to work on an authentic problem to justify their decision to deliver a module online rather than by conventional face-to-face methods alone. They then explore the selection of an appropriate structure and mode of supporting the module for a specific target group of students, and produce a plan for its design, development, and evaluation. Thereafter, they examine how to design appropriate teaching, learning, and assessment strategies and develop exemplar online learning materials for delivery within the proposed online module.

It is felt strongly by the course team involved in the design of this module that of equal, if not more so, importance to these group-product outcomes is the development of the PBL group process online. Developing the participants' ability to reflect on their own and their peers' learning through the creation and maintenance of an online reflective journal is a very important aspect of the module. The online learning environment used for the support of the learning is WebCT ${ }^{\mathrm{TM}}$. It provides the PBL group with an opportunity to enhance their group learning.

The transformational use of the computer as a mediational tool, such as was planned for this module, rather than simply as a mechanism for delivery of content has not been widely implemented 
(Littlejohn, 2002). This is unsurprising since many academics have limited experience of ICT for teaching and learning, and lack familiarity with current thinking in educational technology. Littlejohn argues that this may lead to severe limitations in course design. He continues by stating that there is a need to offer staff opportunities to gain the skills and knowledge required to incorporate new teaching methods within their course design. Taking this into account, instructional design strongly influenced the module. See Figure 1 for a schema of the online problem-based learning module.

Specific communication facilities in the OLE of WebCT ${ }^{\mathrm{TM}}$ were the main supports for the PBL group process. For the 10-week duration of the module, the asynchronous discussion board (bulletin board or fora) and, less frequently, the synchronous chat room were utilised by the group in the exploration of the authentic problem. Relevant information that individual members of the group unearthed on their various information-retrieval jaunts were uploaded to the discussion board for sharing with the whole group. The PBL group then organised a number of synchronous chat sessions, both with and without facilitator support, to discuss pertinent issues about the problem.

The lecturers had all completed a problem-based learning module prior to starting this online learning module. This led the foundations of their knowledge about PBL. They were aware that problem-based learning is centred on a problem that has to engage students' interest, compel them to take it on as their responsibility, support the development and application of problem-solving and conceptual skills, and stimulate self-directed learning into areas of study relevant to the curriculum (Barrows, 1999).

Self-directed learning was an important aspect of the PBL group process. An online library of relevant key articles and reports was initially set up by the module tutor, but this was incrementally developed by the PBL group members themselves as the module progressed, and they discovered further rich resources that deserved sharing with their peers. De Boer and Collis (2002) argue that in higher education learning situations, such submissions become part of the learning resources of others and is a way to engage students more directly in the learning process as contributors as well as consumers of preselected learning materials.
The question can be asked: Why use an online approach for this module in conjunction with faceto-face teaching sessions rather than continue allowing the lecturers to work solely in a face-to-face learning environment? Quite simply, the main idea is to provide them with an opportunity to experience online learning as students, and the problem-based learning aspect played an important role in showing the benefits of collaboration.

We know in adult life that reaching solutions to a complex, ill-structured problem is difficult, time consuming, and often does not have one clear-cut, right answer. To arrive at a viable solution, learners can use the OLE to examine the problem from many angles, gather as much relevant information as is feasible, formulate potential solutions, weigh their consequences, and make a decision. Working collaboratively online in this way is not intended to be an all-encompassing, self-contained problem-based learning environment. Instead, its intent is to engage students and guide them through the basic steps of problem solving while encouraging them to think, research, and experiment away from the computer. Continuing to work online helps generate ideas, provoke thought, store information, assist students in reaching solutions, and helps students present those results to their peers.

Critics of e-learning are quick to point out that many course offerings are nothing but digital pageturners. Some refer to the act of taking an e-learning course as "e-reading." Many reasons are attributed to this prevalent condition-from time and budget constraints to limitations of traditional instructional design. Another important reason could be the lack of exposure to alternative practices, in this instance, PBL.

For problem-based learning and e-learning to work effectively, both require an effective curriculum; curriculum design, and in the case of the latter, instructional design, therefore, is critical to their overall delivery and success.

\section{FUTURE TRENDS}

Several challenges remain in this area despite the substantial promise of Web-based instruction and other information technologies (Hill, 2002). In addition to technological challenges such as consistent 
connections, the pedagogical challenges of dealing with information overload and isolation of learners also exist.

Albion and Gibson (1998) address the problematic nature of certain aspects of PBL in the online environment. They explore the notion that professional expertise, which is an expected outcome of problem-based learning, does need to function in an individual as well as in a group, and they suggest practical technological alternatives for the phase of PBL in which students judge and compare their own ideas on a problem to those of others. They suggest that for PBL to be adopted as a design framework for IMM, there will be a need for intelligent software assistants to monitor and respond to the user.

On a positive side, this research advocates that this module about online learning, delivered using a problem-based learning approach, is a move toward creating a community of learners that can "tap levels of energy that otherwise remain dormant" (Manning, Curtis, \& McMillen, 1996). Many theorists would argue the importance of providing students with authentic experiences: experiences that reflect real-world ways of knowing and doing (Bennett, Harper, \& Hedberg, 2002). It is thought that such experiences allow learners to transfer knowledge from formal education to practice, and so provide opportunities for meaningful learning. However, in designing online learning environments to support these authentic activities, there must be an alignment between the context in which learning is presented in the formal setting and the real-life setting in which that knowledge will be called upon. For this module, the exciting features offered by the online learning environment, WebCT ${ }^{\mathrm{TM}}$, provide a rich supportive environment for authentic learning for the lecturers. It also provides the infrastructure and communication facilities for them to work collaboratively online, as a support to their face-to-face sessions, in a problem-based learning group, giving them a new experience in higher education in this new millennium. Joint database exploration, sharing workspaces, and supporting reflective communication enable individuals to share cognitively with other individuals (Andres, 2002).

In this era of rapid change, we as educators increasingly recognize that students must learn how to develop and apply knowledge creatively, not simply remember what they have been told (Wiske,
Sick, \& Wirsig, 2001). Online learning combined with problem-based learning appears to hold promise in overcoming these issues. A problem-based learning approach can be used online because it is a motivating way to learn for the students; they are involved in active learning, working with real problems encountered in their everyday learning.

This case study has shown that the integration of online and problem-based learning has the potential to create a dynamic, engaging learning environment that is centred on the needs of the student. PBL provides training for students not only in the content of the curriculum area, but also in the development of skills that will enable them to continue to learn and apply what they know as they move through their changing career options. The incorporation of online learning strategies provides a degree of flexibility in the way students can undertake their learning and provides for a collaborative and interactive environment. It also allows students to develop skills in the actual application of modern information and communications technologies that result in real achievements. Problem-based learning online is the vocational training for the problem solvers of tomorrow.

\section{CONCLUSION}

In this overview, the author summarized the evolvement of the integration of problem-based learning and online learning in higher education. A number of elements are important for the successful integration of these areas: Following the principles of constructivism and engagement are vital to create collaborative and authentic learning for learners in such courses. The self-directed learning focus of PBL, combined with the capabilities of today's online learning environments, can turn out learners who are motivated, know what they want to learn, set their objectives, find resources, and evaluate their learning progress to meet their goals-all collaboratively and virtually. Some problematics do remain to be overcome: the robustness of the technology, the importance of sound pedagogical design to promote a community of learners, and the role of the individual learner in a group. However, the research would seem to indicate that the inherent benefits of merging these two approaches can and do outweigh any shortcomings. 


\section{REFERENCES}

Albion, P., \& Gibson, I. (1998). Designing multimedia material using a problem-based learning design. Proceedings of ASCILITE conference, 1998. Retrieved from http://www./conference/ASCILITE/ papers/

Andres, Y. M. (2002). Art of collaboration: Awesome tools and proven strategies. TechEd. Retrieved from http://techedevents.org/LongBeach/ Proceedings/RT\%20804.pdf

Atkinson, T. (2001). Creating online virtual environments for inquiry-based learning. EDUCAUSE: Effective practices and solutions. Retrieved from h t t p : / / www. educause. edu/ep/ ep_item_detail.asp?ITEM_ID=73

Barrows, H. (1986). A taxonomy of problem-based learning methods. Medical Education, 20, 481486.

Barrows, H. (1999). Problem-based learning: A total approach to education. Springfield, IL: Southern Illinois University School of Medicine.

Bennett, S., Harper, B., \& Hedberg, J. (2002). Designing real life cases to support authentic design activities. Australian Journal of Educational Technology, 18(1), 1-12.

Boud, D., \& Feletti, D. (Eds.). (1991). The challenge of problem-based learning. London: Kogan Page.

Central Queensland University Online Collaborative Learning in Higher Education. (n.d.). Retrieved May 5, 2004, from http://pbl.cqu.edu.au/content/ online_resources.htm

Chuang, W. (2002). An innovative teacher training approach: Combine live instruction with a Webbased reflection system. British Journal of Educational Technology, 33(2), 229-232.

Collis, B., \& Winnips, K. (2002). Two scenarios for productive learning environments in the workplace. British Journal of Educational Technology, 33(2), 133-148.

De Boer, W., \& Collis, B. (2002). A changing pedagogy in e-learning: From acquisition to contribu- tion. Journal of Computing in Higher Education, 13(2), 87-101.

Dillenbourg, P. (1999). What do you mean by collaborative learning? In P. Dillenbourg (Ed.), Collaborative learning: Cognitive and computational approaches. Oxford: Pergamon.

Gardner, L., Sheridan, D., \& White, D. (2002). A Web-based learning and assessment system to support flexible education. Journal of Computer Assisted Learning, 18, 125-136.

Geelan, D., \& Taylor, P. (2001). Embodying our values in our teaching practices: Building open and critical disclosure through computer mediated communication. Journal of Interactive Learning Research, 12(4), 375-401.

Grabinger, R., \& Dunlap, J. (2000). Rich environments for active learning: A definition. In D. Squires, G. Conole, \& G. Jacobs (Eds.), The changing face of learning technology. University of Wales Press.

Hedberg, J. (2000). Creating motivating interactive learning environments. Australia: University of Wollongong.

Hill, J. (2002). Overcoming obstacles and creating connections: Community building in Web-based learning environments. Journal of Computing in Higher Education, 14(1), 67-86.

Jonassen, D. (1997). Instructional design models for well-structured and ill-structured problem-solving learning outcomes. ETR \& D, 45(1), 65-94.

Lehtinen, E., Hakkarinen, K., Lipponen, L., Rahikainen, M., \& Muukkonen, H. (1999). Computer supported collaborative learning: A review of research and development. In J. H. G. I. Giebers (Ed.), Reports on education (p. 10). The Netherlands: Department of Educational Science, University of Mijmegen.

Littlejohn, A. (2002). Improving continuing professional development in the use of ICT. Journal of Computer Assisted Learning, 18, 166-174.

Littleton, K., \& Light, P. (1999). Learning with computers: Analysing productive interaction. London \& New York: Routledge.

McMaster University Problem Based Learning 
Online Resources. (n.d.). Retrieved from http:// www.fhs.mcmaster.ca/facdev/educational.html

Ocker, R., \& Yaverbaum, G. (2001). Collaborative learning environments: Exploring student attributes and satisfaction in face-to-face and asynchronous computer conferencing settings. Journal of Interactive Learning Research, 12(4), 427-448.

Savery, J., \& Duffy, T. (1995, September-October). Problem-based learning: An instructional model and its constructivist framework. Educational Technology, 31-38.

Trentin, G. (2001). From formal training to communities of practice via network-based learning. Educational Technology, 41(2), 5-14.

Vernon, D., \& Blake, R. (1993). Does problembased learning work? A meta-analysis of evaluative research. Academic Medicine, 68(7), 550-563.

Wiske, M., Sick, M., \& Wirsig, S. (2001). New technologies to support teaching for understanding. International Journal of Educational Research, 35, 483-501.

\section{KEY TERMS}

Collaborative Learning: Collaborative learning is a personal philosophy, not just a classroom technique. In all situations where people come together in groups, it suggests a way of dealing with people that respects and highlights individual group members' abilities and contributions. There is a sharing of authority and acceptance of responsibility among group members for the groups' actions. The underlying premise of collaborative learning is based upon consensus building through cooperation by group members, in contrast to competition in which individuals best other group members.

Computer-Supported Cooperative Learning (CSCL): CSCL is combining communications and computer technologies to support various activities involving groups in collaborative problem-solving situations.

Constructivism: Constructivism is an educational theory concentrated on assisting students in constructing meaning through experiential and selfdirected means.

Higher Education: Higher education refers to education at degree level and above. Higher education courses are those leading to the award of a bachelor's degree, graduate certificate, graduate diploma, master's degree, or doctoral degree. Some courses leading to the award of a diploma or advanced diploma may also be accredited as higher education. In the Republic of Ireland, a majority of all higher education is offered by universities and colleges of technology.

\section{Hypothetico-Deductive Reasoning:} Hypothetico-deductive reasoning is, given a particular situation, applying relevant knowledge of principles and constraints, and visualizing, in the abstract, the plausible outcomes that might result from various changes one can imagine to be imposed on the system.

Online Learning Environment (OLE): An online learning environment is one that goes beyond the replication of learning events that have traditionally occurred in the classroom and are now made available through the Internet. It provides for different ways of learning and the construction of a potentially richer learning environment that provides for fresh approaches to learning, caters to different learning styles, as well as allowing for greater diversification in learning and greater access to learning.

Problem-Based Learning (PBL): Problembased learning is a pedagogical strategy for posing significant, contextualized, real-world situations, and providing resources, guidance, and instruction to learners as they develop content knowledge and problem-solving skills. 